\title{
Expression and significance of the imprinted gene PEG10 in placenta of patients with preeclampsia
}

\author{
X.Y. Liang, X. Chen, Y.Z. Jin, X.O. Chen and Q.Z. Chen \\ Baoshan Branch Obstetrics and Gynecology Department, \\ Shanghai First People's Hospital, Shanghai, China \\ Corresponding author: X. Chen \\ E-mail: XiongChencn@126.com
}

Genet. Mol. Res. 13 (4): 10607-10614 (2014)

Received June 10, 2013

Accepted October 29, 2013

Published December 18, 2014

DOI http://dx.doi.org/10.4238/2014.December.18.2

\begin{abstract}
The aim of this study was to investigate the expression and significance of the imprinted gene PEG10 (paternally expressed gene 10) in preeclampsia placental tissue. Quantitative real-time reverse transcriptase polymerase chain reaction and immunohistochemistry to evaluate mRNA and protein expression and distribution of PEG10 in placental tissues obtained from 22 preeclampsia patients (8 patients with mild preeclampsia, 14 cases of severe preeclampsia). At the same time, 22 cases of normal pregnant women served as controls. PEG10 expression was determined in the placental tissue of the two different groups. In the normal pregnancy group, the average expression level of PEG10 was $0.5832 \pm 0.045$, while in the preeclampsia group, this level was $0.1943 \pm 0.035$. Statistical analysis showed that the two groups differed significantly $(\mathrm{P}<0.05)$. The downregulated expression of the imprinted gene PEG10 may be an important reason for the occurrence of preeclampsia.
\end{abstract}

Key words: Imprinted genes; Preeclampsia; PEG10; Trophoblastic cells 


\section{INTRODUCTION}

Preeclampsia is a peculiar disease. According to statistics, its incidence is 9.4$10.4 \%$ in China, while it is as high as $7-12 \%$ during pregnancy in other countries (Ronsmans and Campbell, 2011). Although studies of etiology and prevention of preeclampsia have made some progress, there are no effective means of prevention and clinical treatment besides such measures as conventional spasmolytics, depressurization, and termination of pregnancy. With the placenta out of the uterus, the symptoms of preeclampsia disappear. Therefore, some scholars think that pathophysiological changes in the placenta are the basis of the pathogenesis of preeclampsia (Steinhoff et al., 2009). Currently, it is well accepted that the center of the pathogenesis of preeclampsia is the placental "shallow bed". During normal pregnancy, the uterine spiral arteries are transformed into high capacity and low impedance blood vessels by surrounding trophoblastic cells to increase blood flow and meet the needs of fetal nutrition. The weakened ability of trophoblastic cells to infiltrate leads to the disorder of placental vascular bed remodeling of uterine spiral arteries and may be a key factor in preeclampsia (Shaman et al., 2013).

We found that there are many highly expressed genes in the gene expression spectrum (Affymetrix chips) of cytotrophoblastic cells in normal pregnancy and extra villous trophoblastic cells, and PEG10 is one of them (Fan et al., 2007). Besides, PEG10 may be involved in pathological pregnancy of inevitable abortion (Liang et al., 2008). Moreover, Ono et al. (2006) found that placental function defects caused by the lack of PEG10 in mice subjected to gene knockout could result in early embryonic death. These results indicated that PEG10 plays an important role in pregnancy (Lim et al., 2012). Preeclampsia is a special kind of pathological pregnancy, where the main mechanism is closely related to the infiltrating ability of the trophoblastic cell (Shaman et al., 2013). PEG10 is highly expressed in the gene expression spectrum of the trophoblastic cell. It is not known whether PEG10 has a high expression in preeclampsia placental tissue and whether it participates in the regulation of the trophoblastic cell in placental tissue. Therefore, this research aimed to explore the role of the imprinted gene from fathers in the pathogenesis of preeclampsia, using quantitative RT-PCR, immunohistochemical assay and immune imprinting to analyze the expression levels of PEG10 mRNA and protein in placental tissue of patients with preeclampsia and normal pregnancy women at the same time, and then to further explore the pathogenesis of preeclampsia. Early detection and timely treatment of preeclampsia is needed to reduce mortality. Perinatal infant mortality will ultimately be reduced.

\section{MATERIAL AND METHODS}

\section{Clinical data}

From August 2010 to June 2012, 22 patients with preeclampsia (8 patients with mild preeclampsia and 14 cases of severe preeclampsia) who had a vaginal delivery were selected in the Obstetrics and Gynecology Department of the First People's Hospital, Shanghai Baoshan Branch, as the study group. Another 22 cases of normal full-term pregnancy women who underwent cesarean section during the same period served as the con- 
trol group. All subjects had a singleton pregnancy. In the study group, the gestational ages of the patients were from 29 to 39 weeks, with a mean of $34.2 \pm 3.3$ weeks; the ages were from 21 to 33 years old, with a mean of $26.5 \pm 3.2$ years; motherhood was $1-6$ times, with an average maternal time of $3.2 \pm 1.4$. In the control group, the gestational ages of the women were from 38 to 40.4 weeks, with a mean of $39.1 \pm 0.7$ weeks; the ages were from 20 to 36 years old, with an average of $27.1 \pm 2.6$ years; motherhood was 1-7 times, with an maternal time of $3.4 \pm 1.8$. Difference in age and motherhood time between the two groups was not statistically significant $(\mathrm{P}>0.05)$. Preeclampsia diagnostic criteria was according to the National College Books "Obstetrics and Gynecology" Version 7 (Le, 2008). The two groups of pregnant women had no previous history of adverse pregnancy, primary hypertension, diabetes, chronic nephritis, heart and immune system diseases or other chronic diseases. There was no history of blood transfusion and immunotherapy. All subjects signed informed consent, and the ethics committee of our hospital examined and approved the study.

\section{Specimen processing}

All specimens were from vaginal delivery placenta and obtained within 15 min. Sterile scissors were used to cut 3 to 4 pieces from the placental umbilical cord attached to the surface of the root area of maternal central parts. Besides, a $1.0 \mathrm{~cm}$ cubed piece was cut to avoid the area of hemorrhage, necrosis and calcification. The tissue was dissected and washed in PBS until it was clean. Specimen was treated with DEPC water and disinfection of frozen pipes, and the rest was rapidly frozen in liquid nitrogen, transferred to a $-80^{\circ} \mathrm{C}$ freezer and stored overnight. Fresh tissue specimens of approximately $1.5 \mathrm{~cm}$ cubed pieces were fixed in $4 \%$ paraformaldehyde for immunohistochemical assays.

\section{Method}

\section{PEG10 protein levels determined by immunohistochemistry}

Small pieces of paraformaldehyde-fixed placental tissue were dehydrated, paraffinembedded, and serially sectioned at $5 \mu \mathrm{m}$ the slide is prevented by cleaning treatment, APES package and in case of off-chip. Three slices of each tissue were used for the following SP immunohistochemical staining procedures. The main steps were as follows. Sections were deparaffinaged and placed in a microwave $(800 \mathrm{~W})$ for three cycles $(5 \mathrm{~min}$ each). Endogenous peroxidase activity was blocked $(3 \% \mathrm{H} 2 \mathrm{O} 2,5 \mathrm{~min})$ prior to incubation at room temperature overnight with mouse anti-human PEG10 monoclonal antibody (1:100, Beijing Zhongshan) and then with biotinylated rabbit anti-mouse IgG (1:200, Beijing Zhongshan) at room temperature for $1 \mathrm{~h}$ at $37^{\circ} \mathrm{C}$, followed by color development with $\mathrm{DAB} / \mathrm{H} 2 \mathrm{O} 2$. Reactions were stopped by repeated washing in PBS. The slides were counterstained with hematoxylin. When the negative control was incubated with diluent instead of antibody, the reaction was negative. Five high-power fields (100X) were randomly selected under a light microscope for observation and subjected to photographic color image analysis by using Image-Pro Plus Version 5.1. For each slice, the absorbance of the PEG10 immune reaction product was measured and subjected to semi-quantitative statistical analysis. 


\section{Real-time quantitative PCR (real-time FQ-PCR) used to detect PEG10 mRNA}

\section{Total RNA extraction and reverse transcription reaction}

In accordance with the Trizol reagent instructions, total RNA was extracted from placental tissue, and RNA concentration and purity were evaluated with a UV spectrophotometer, followed by storage at $-70^{\circ} \mathrm{C}$. cDNA synthesis was carried out with a reverse transcription kit (Takara). The cDNA product obtained was stored at $-80^{\circ} \mathrm{C}$ until RT FQ-PCR assay.

\section{RT FQ-PCR primer design, mRNA determination, and data analysis}

The standard sample preparation and standard curve analysis were performed by the Haiyidikang Company. The primers were as follows: PEG10-1F, GCTACCACTGCCGGATGTAT; PEG10-1R, GCCACAAAATCTCGAAGAGC. The PEG10 and ß-actin reaction systems and reaction conditions were the same. The amplification reaction conditions consisted of initial denaturation at $95^{\circ} \mathrm{C}$ for $10 \mathrm{~min}$, followed by 40 cycles of $94^{\circ} \mathrm{C}$ for $15 \mathrm{~s}, 56^{\circ} \mathrm{C}$ for $20 \mathrm{~s}, 72^{\circ} \mathrm{C}$ for $30 \mathrm{~s}$ to collect the fluorescence signal. mRNA levels were determined by calculating the relative expression of the target gene mRNA: $\Delta \mathrm{CT}$ (target gene) $=$ target gene $\mathrm{CT}$ - an endogenous control gene $\mathrm{Ct}, \Delta \Delta \mathrm{C}^{\mathrm{t}}=\left(\mathrm{C}^{\mathrm{t}}\right.$ (target gene) $-\Delta \mathrm{C}^{\mathrm{t}}$ (standard value), giving the target gene relative total of $2^{-\Delta \Delta C T}$. Data analysis was carried out with the accompanying Roche LightCycleR 480 Software.

\section{Statistical analysis}

Data are reported as means \pm SD. The SPSS 13.0 software was used for statistical analysis, and the groups were compared using a $t$-test, where $\mathrm{P}<0.05$ was statistical significance to be statistically significant.

\section{RESULTS}

\section{PEG10 mRNA expressions in the placenta}

Real-time FQ-PCR, immunohistochemistry and Western blot showed that PEG10 was expressed in the placenta of both groups (preeclampsia group and normal pregnancy group) (Figure 1). Levels in the normal pregnancy group were higher than in the preeclampsia group and the difference was statistically significant $(\mathrm{P}<0.05)$, as shown in Table 1 .

\section{PEG10 protein expressions in the placenta}

Immunohistochemical results showed the expression of the PEG10 protein in placental tissue of the two different groups (normal pregnancy and preeclampsia group). However, the preeclampsia group showed significantly lower levels than the normal pregnancy group ( $\mathrm{P}$ $<0.05$ ), as shown in Table 1. Light microscopy showed PEG10 protein expression in stromal cells and glandular epithelial cells (brown staining), with the nucleus not stained. Normal pregnancy placental tissue showed strongly positive expression $(+++)$; preeclampsia tissue showed weakly positive expression $(+)$ (Figure 2 ). Western blot showed in each sample bands 
at $55 \mathrm{kDa}$ and $43 \mathrm{kDa}$, representing the target protein. GenBank (code: BAB43951.1) showed the PEG10 ORF1 protein size to be consistent (Figure 3).

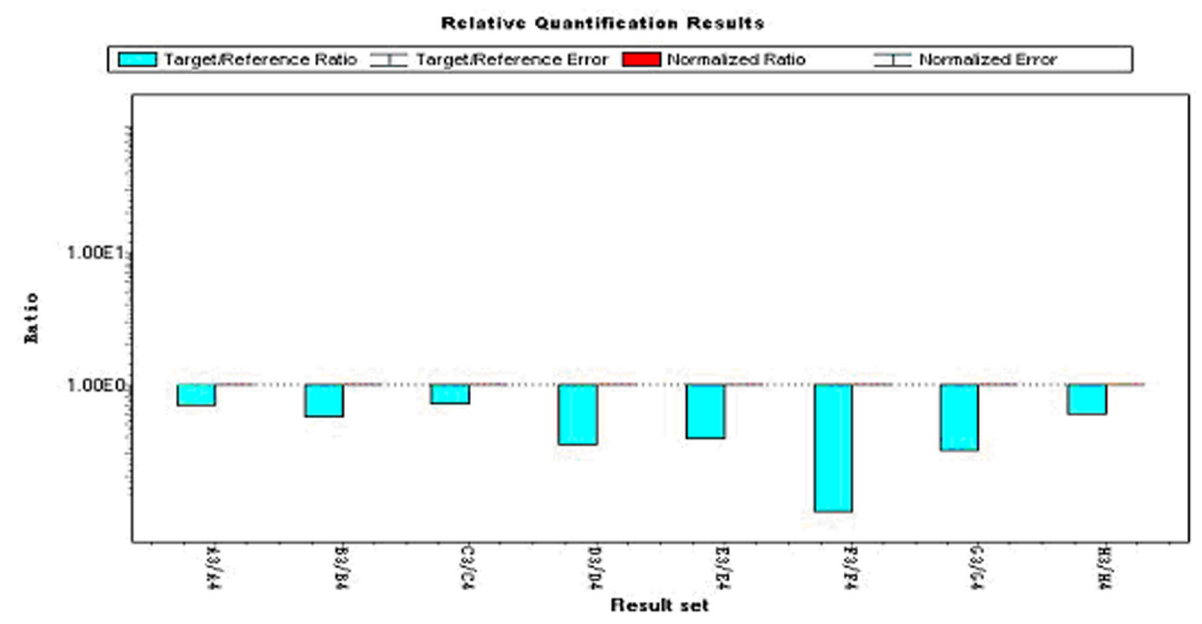

Figure 1. PEG10 relative expression in the placental tissue of preeclampsia and normal pregnancy. Severe preeclampsia: A3/A4, B3/B4, C3/C4, H3/H4; Mild preeclampsia: D3/D4, E3/E4, the G3/G4; Normal pregnancy: F3/F4.

Table 1. PEG10 expression levels in the placental tissue of preeclampsia patients and normal pregnant women.

\begin{tabular}{lccc}
\hline Groups & Semi-quantitative reverse transcriptase polymerase chain reaction & Immunohistochemistry & Western blot \\
\hline Preeclampsia & $0.1943 \pm 0.035$ & $0.0572 \pm 0.005$ & $0.0384 \pm 0.015$ \\
Normal pregnancy & $0.5832 \pm 0.045$ & $0.1258 \pm 0.086$ & $0.1052 \pm 0.036$ \\
P & $<0.001$ & $<0.001$ & $<0.001$
\end{tabular}

Data are reported as means $\pm \mathrm{SD}$.

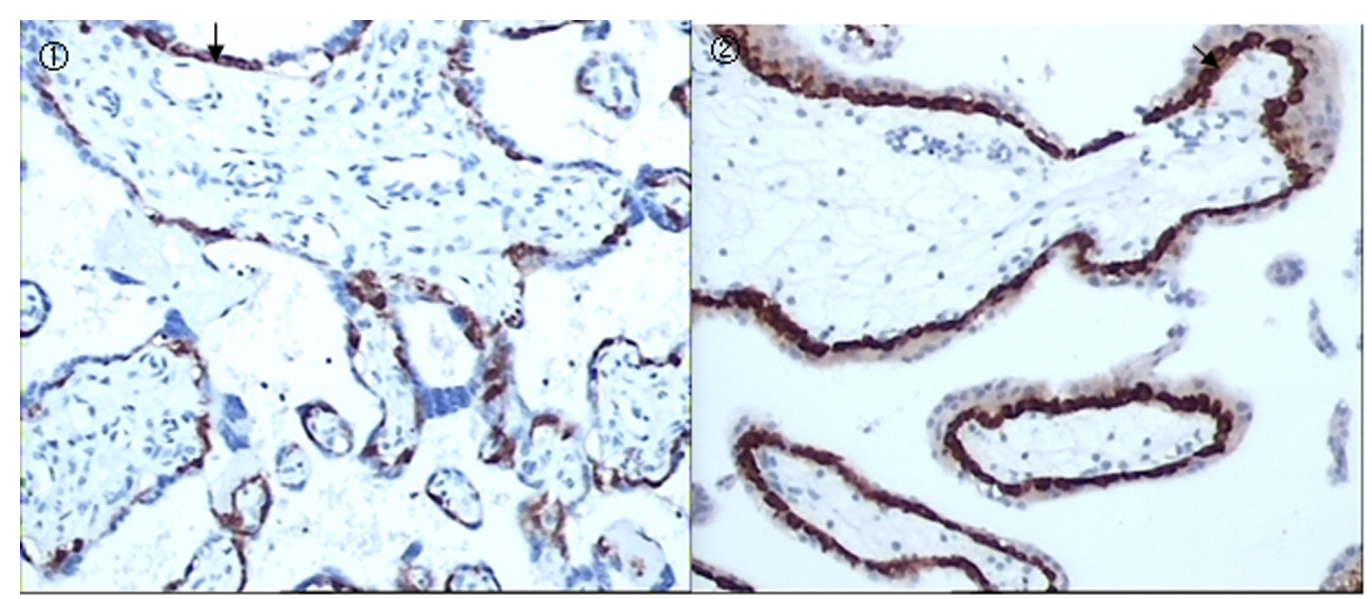

Figure 2. 1) PEG10 expression in the preeclampsia placenta tissue 100X; 2) PEG10 expression in normal pregnancy placental tissue $100 \mathrm{X}$. 

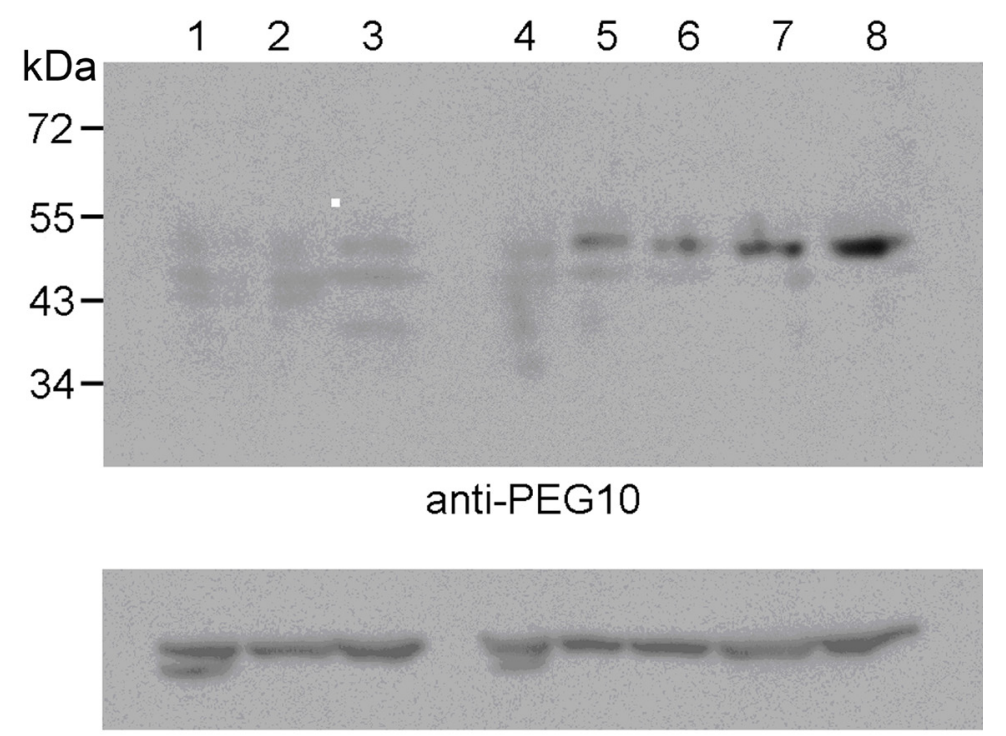

anti-ßactin

Figure 3. Analysis of the expression of PEG10 protein in normal pregnancy and preeclampsia tissues by Western blot. 1 to 4: Western blot product from severe the preeclampsia placental tissue; 5 and 6: Western blot product from mild preeclampsia placental tissue; 7 and 8: normal full-term pregnancy placental tissue products.

\section{DISCUSSION}

From an immunological point of view, the maternal-fetal interface constituted by maternal decidua tissue and placental trophoblastic tissue is the basis for pregnancy immune tolerance. DiFederico et al. (1999) found that there were few apoptotic trophoblastic cells outside the villus in the decidua of the normal pregnancy group. However, about $15-50 \%$ of trophocytes outside the villi are apoptotic in placental tissue in patients with preeclampsia. Increased cell apoptosis makes the trophocyte invasion incomplete, which limits the infiltration depth and causes remodeling of the spiral arteriolar wall as well as shallow placental implantation (Zheng et al., 2005). Sertoli cells moderately penetrate the uterine muscular layer, which leads to remodeling of the spiral arteriolar wall in the placenta. It is a necessary to maintain normal pregnancy. However, the reduction in the capacity mentioned above can lead to corresponding pregnancy complications such as preeclampsia and intrauterine fetal growth restriction and so on (Norwitz, 2006). In addition, we found defects in androgenize embryonic development after the androgenetic embryo was transplanted into the uterus. When the extraembryonic cell line-trophoblastic cells overgrow, they have more stronger ability to infiltrate in the uterus, which makes the placenta larger. The ability of the single female reproductive animals sertoli cells and placentation is lacking. This suggests that the source of paternally imprinted genes mainly adjusts the growth of the trophoblastic cell leaf and placentation nourishes (Fowden et al., 2006).

PEG10 is an important imprinted gene with the characteristics of paternal expression and maternal imprinting (Ono et al., 2001). Kikuno et al. (1999) cloned it in 1999, which is 
located on human chromosome 7q21 and mouse chromosome 6A1. PEG10 encodes at least two proteins such as PEG10 RF1 and PEG10 RF1/2 (Clark et al., 2007). Many reports about PEG10 with respect to tumors have been published (Ip et al., 2007; Kainz et al., 2007). There is a striking resemblance between the invasion behavior of the trophoblastic cell and the metastatic behavior of tumors. This includes the identification, adhesion and degradation of extracellular matrix and intrusion into the vascular endothelial and so on. This causes maternal blood vessel reconstruction and opens the placental blood supply. PEG10 has been proven to be one of the important control genes and target genes, which are affected by the original cancer gene (Hu et al., 2004; Li et al., 2006). In this study, PEG10 as a gene that comes from the father but is imprinted by the mother, showed much lower mRNA and protein levels in preeclampsia placenta tissue than that in the normal pregnancy group. This indicates that the loss of PEG10 may be an important regulatory event in preeclampsia. Its mechanism may be that the loss of PEG10 induces apoptosis, and mediated by the method of siRNA, it led to increased cell apoptosis (Lux et al., 2010). Excessive expression of PEG10 - RF1 protein plays an anti-apoptosis role and promotes cell growth (Clark et al., 2007). PEG10 disrupts the balance of sertoli cell proliferation and apoptosis. Thus, the ability of the sertoli cell to invade the spiral artery is impaired and the remodeling of the placental spiral arteriolar wall is blocked. It causes shallow implantation of the placenta, placental ischemia and hypoxia, leading to preeclampsia. In addition, some in vitro studies have proven that hypoxia and ischemia reperfusion can cause sertoli cell apoptosis (Heazell et al., 2008). Hence, we infer that it will lead to the expression disorders of PEG10 and abnormal sertoli cell proliferation if the expression of PEG10 in placenta tissue cannot be maintained at a certain level, thus inducing preeclampsia. Placental ischemia and anoxia in preeclampsia patients further exacerbate sertoli cell apoptosis. Whether the loss of PEG10 is the central control point of this vicious circle and whether the recovery of PEG10 expression can improve the condition of preeclampsia patients and thus reduce perinatal morbidity and mortality are questions that remain to be further studied.

\section{ACKNOWLEDGMENTS}

Research supported by the Science and Technology Commission, Baoshan District, Shanghai (\#2010-E-21).

\section{REFERENCES}

Clark MB, Janicke M, Gottesbuhren U, Kleffmann T, et al. (2007). Mammalian gene PEG10 expresses two reading frames by high efficiency -1 frameshifting in embryonic - associated tissues. J. Biol. Chem. 282: 37359-37369.

DiFederico E, Genbacev O and Fisher SJ (1999). Preeclampsia is associated with widespread apoptosis of placental cytotrophoblasts within the uterine wall. Am. J. Pathol. 155: 293-301.

Fan CB, He JL, Wang YX, Liu XQ, et al. (2007). Gene expression profiles analysis related to invasion of trophoblasts. Cell Biol. 29: 97-102.

Fowden AL, Sibley C, Reik W and Constancia M (2006). Imprinted genes, placental development and fetal growth. Horm. Res. 65 (Suppl. 3): 50-58.

Heazell AE, Buttle HR, Baker PN and Crocker IP (2008). Altered expression of regulators of caspase activity within trophoblast of normal pregnancies and pregnancies complicated by preeclampsia. Reprod. Sci. 15: 1034-1043.

Hu C, Xiong J, Zhang L, Huang B, et al. (2004). PEG10 activation by co-stimulation of CXCR5 and CCR7 essentially contributes to resistance to apoptosis in $\mathrm{CD} 19^{+} \mathrm{CD} 34^{+} \mathrm{B}$ cells from patients with $\mathrm{B}$ cell lineage acute and chronic lymphocytic leukemia. Cell Mol. Immunol. 1: 280-294.

Ip WK, Lai PB, Wong NL, Sy SM, et al. (2007). Identification of PEG10 as a progression related biomarker for 
hepatocellular carcinoma. Cancer Lett. 250: 284-291.

Kainz B, Shehata M, Bilban M, Kienle D, et al. (2007). Overexpression of the paternally expressed gene 10 (PEG10) from the imprinted locus on chromosome 7q21 in high-risk B-cell chronic lymphocytic leukemia. Int. J. Cancer 121: 1984-1993.

Kikuno R, Nagase T, Ishikawa K, Hirosawa M, et al. (1999). Prediction of the coding sequences of unidentified human genes. XIV. The complete sequences of 100 new cDNA clones from brain which code for large proteins in vitro. DNA Res. 6: 197-205.

Le J (2008). Obstetrics and Gynecology. 7th edn. People's Medical Publishing House, Beijing.

Li CM, Margolin AA, Salas M, Memeo L, et al. (2006). PEG10 is a c-MYC target gene in cancer cells. Cancer Res. 66: 665-672.

Liang XY, Liu XQ, Ding YB, Chen XM, et al. (2008). Genetic imprinted gene PEG10 expression in deciduas from inevitable abortion. Yi Chuan 30: 735-740.

Lim AL, Ng S, Leow SC, Choo R, et al. (2012). Epigenetic state and expression of imprinted genes in umbilical cord correlates with growth parameters in human pregnancy. J. Med. Genet. 49: 689-697.

Lux H, Flammann H, Hafner M and Lux A (2010). Genetic and molecular analyses of PEG10 reveal new aspects of genomic organization, transcription and translation. PLoS One 5: e8686.

Norwitz ER (2006). Defective implantation and placentation: laying the blueprint for pregnancy complications. Reprod. Biomed. Online 13: 591-599.

Ono R, Kobayashi S, Wagatsuma H, Aisaka K, et al. (2001). A retrotransposon-derived gene, PEG10, is a novel imprinted gene located on human chromosome 7q21. Genomics 73: 232-237.

Ono R, Nakamura K, Inoue K, Naruse M, et al. (2006). Deletion of Peg10, an imprinted gene acquired from a retrotransposon, causes early embryonic lethality. Nat. Genet. 38: 101-106.

Ronsmans C and Campbell O (2011). Quantifying the fall in mortality associated with interventions related to hypertensive diseases of pregnancy. BMC Public Health 11 (Suppl. 3): S8.

Shaman A, Premkumar BJ and Agarwal A (2013). Placental Vascular Morphogenesis and Oxidative Stress. In Studies on Women's Health Oxidative Stress in Applied Basic Research and Clinical Practice (Agarwal A, Aziz N and Rizk B, eds.). Humana Press, New York, 95-113.

Steinhoff C, Paulsen M, Kielbasa S, Walter J, et al. (2009). Expression profile and transcription factor binding site exploration of imprinted genes in human and mouse. BMC Genomics 10: 144.

Zheng J, Bird IM, Chen DB and Magness RR (2005). Angiotensin II regulation of ovine fetoplacental artery endothelial functions: interactions with nitric oxide. J. Physiol. 565: 59-69. 